Illinois State University

ISU ReD: Research and eData

Theses and Dissertations

$9-22-2020$

\title{
Right-Wing Authoritarianism, Moral Disengagement, And Victimization: The Demeaning Socio-Cognitive Attitudes Of Bullies
}

Megan E. Donnelly

Illinois State University, megandonnelly1003@gmail.com

Follow this and additional works at: https://ir.library.illinoisstate.edu/etd

Part of the Psychology Commons

\section{Recommended Citation}

Donnelly, Megan E., "Right-Wing Authoritarianism, Moral Disengagement, And Victimization: The Demeaning Socio-Cognitive Attitudes Of Bullies" (2020). Theses and Dissertations. 1330.

https://ir.library.illinoisstate.edu/etd/1330

This Thesis is brought to you for free and open access by ISU ReD: Research and eData. It has been accepted for inclusion in Theses and Dissertations by an authorized administrator of ISU ReD: Research and eData. For more information, please contact ISUReD@ilstu.edu. 


\title{
RIGHT-WING AUTHORITARIANISM, MORAL DISENGAGEMENT, AND VICTIMIZATION: THE DEMEANING SOCIO-COGNITIVE \\ ATTITUDES OF BULLIES
}

\author{
Megan E. Donnelly
}

\section{Pages}

Objective: To examine the socio-cognitive attitudes of Right-wing authoritarianism and moral disengagement as they relate to bullying victimization and perpetration within the high school context. Method: Ninth grade students $(N=212 ; 50 \%$ male) at a public Midwest high school completed self-report measures during study hall assessing their levels of Right-wing authoritarianism, moral disengagement, and the frequency with which they were involved (i.e., as perpetrators and victims) in bullying both online and in person within the last month. The current study utilized a moderated mediation model to examine the effects of Right-wing authoritarian and morally disengaged attitudes on the school-based bullying ecology. Results: Self-reported bullying perpetration was highly correlated with the teen's sense of victimization, indicating that students who admit to bullying others tend to feel victimized themselves. Further, the effect of Right-wing authoritarianism on bullying perpetration is partially explained by teen sense of aggrievement, and this indirect effect was most pronounced for those with a higher sense of moral disengagement. Conclusions: Findings emphasize that socio-cognitive attitudes such as Right-wing authoritarianism exist among adolescents and may influence their behavior, an important factor to consider when creating and implementing anti-bullying supports. Parents and educators alike should be concerned about the spread of hateful rhetoric on social media, and 
future research should examine teens' individual differences in vulnerability to such harmful messages.

KEYWORDS: Bullying, moral disengagement, right-wing authoritarianism, socio-cognitive attitudes, victimization 
RIGHT-WING AUTHORITARIANISM, MORAL DISENGAGEMENT, AND VICTIMIZATION: THE DEMEANING SOCIO-COGNITIVE

ATTITUDES OF BULLIES

MEGAN E. DONNELLY

\begin{abstract}
A Thesis Submitted in Partial
Fulfillment of the Requirements for the Degree of

MASTER OF SCIENCE

Department of Psychology

ILLINOIS STATE UNIVERSITY
\end{abstract}


(C) 2020 Megan E. Donnelly 
RIGHT-WING AUTHORITARIANISM, MORAL DISENGAGEMENT, AND VICTIMIZATION: THE DEMEANING SOCIO-COGNITIVE ATTITUDES OF BULLIES

MEGAN E. DONNELLY

COMMITTEE MEMBERS:

Steven E. Landau, Chair

Dan Lannin 


\section{ACKNOWLEDGMENTS}

Writing this thesis would not have been possible without the incredible amount of support I received along the way. My most sincere thanks to the following:

My thesis chair, Dr. Steve Landau, for his guidance throughout the research process. His feedback and encouragement have pushed me to be a better writer and researcher;

Committee member Dr. Dan Lannin, who made statistics, and research in general, a lot less intimidating;

Dr. Jeremy Kanter, for his statistics expertise;

Dr. Dawn McBride, for her thoughtful feedback;

My colleagues and friends in the Illinois State University School Psychology program, who have turned into family. I am truly grateful to be part of such a wonderful community;

My forever friends, Emilie, Keeley, Kathy, Shanté, Sam, Julia, Anthony, Bradley, Jeremy, Mark, Mikey, Amber, Morgan, and many cherished others for their unwavering support and irreplaceable friendship each and every day.

My boyfriend, Adrian, who has supported me every step of the way;

My sister, Caitlyn, for the laughs and duets;

My grandparents, Grandma Squeaky, Papa Tom, Grandma Barb, and Papa Jack, for their endless support and love;

My parents, Sherry and Mike, who have always gone above and beyond to help me achieve my dreams. Words cannot express how grateful I am to be their daughter.

And, of course, my beloved pup, Tortellini, who slept on my laptop as I wrote this thesis.

M.E.D 


\section{CONTENTS}

Page

ACKNOWLEDGMENTS

CONTENTS

TABLES $\quad$ iv

FIGURES

CHAPTER I: INTRODUCTION 1

CHAPTER II: REVIEW OF THE LITERATURE

$\begin{array}{ll}\text { Bullying } & 5\end{array}$

Right-wing Authoritarianism 99

$\begin{array}{ll}\text { Moral Disengagement } & 12\end{array}$

Overview of the Present Study 14

$\begin{array}{ll}\text { CHAPTER III: METHOD } & 18\end{array}$

$\begin{array}{ll}\text { Participants } & 18\end{array}$

$\begin{array}{ll}\text { Measures } & 18\end{array}$

Bullying and Cyberbullying Scale for Adolescents (BCS-A) 18

Right-wing Authoritarianism Scale (RWA SCALE) 19

$\begin{array}{ll}\text { Moral Disengagement Scale (MDS) } & 19\end{array}$

$\begin{array}{ll}\text { Procedure } & 20\end{array}$

$\begin{array}{ll}\text { Analytic Approach } & 21\end{array}$

CHAPTER IV: RESULTS 23

$\begin{array}{ll}\text { Descriptive Analyses } & 23\end{array}$

$\begin{array}{ll}\text { Main Analyses } & 24\end{array}$ 
APPENDIX A: ALTERED BULLYING AND CYBERBULLYING SCALE FOR

ADOLESCENTS (BCS-A; THOMAS, SCOTT, COATES, \& CONNOR, 2019)

APPENDIX C: ABBREVIATED MORAL DISENGAGEMENT SCALE (MDS; BANDURA

ET AL., 1996) 


\section{TABLES}

Table Page

1. Means, Standard Deviations, and Zero Order Correlations of Study Measures (N=212) 23 


\section{FIGURES}

Figure

1. Hypothesized mediation model wherein perceived victim experiences mediate the relationship between RWA and self-reported bullying behaviors

2. Hypothesized moderated mediation model wherein moral disengagement moderates the effect of RWA on self-reported bullying behavior that is indirectly mediated by one's sense of victimization

3. Hypothesized moderated moderation model wherein moral disengagement moderates the direct effect of RWA on self-reported bullying behaviors

4. PROCESS Model 8 Conceptual Diagram (Hayes, 2017)

5. PROCESS Model 8 Statistical Diagram (Hayes, 2017)

6. Moderated mediation model 


\section{CHAPTER I: INTRODUCTION}

Content on social media platforms and within current political discourse display an troubling increase in divisive and hateful rhetoric. This may be due, in part, to increased demonstration and endorsement of Right-wing authoritarianism (RWA) by those in power. Right-wing authoritarianism, characterized by submission to strong authority figures, aggression toward others that is approved by authority figures, and strong adherence to social conventions (Altemeyer, 1981) has become associated with prejudice, discrimination, and hostility toward individuals not directly in one's “in-group” (Duckitt \& Sibley, 2007; Crawford, Brandt, Inbar, \& Mallinas, 2016; McCullough, Dispenza, Chang, \& Zeligman, 2019; Whitley, 1999). This hostility is not limited to the political arena, however, as school-based hostility and bullying have recently increased (Southern Poverty Law Center, 2016). Thus, it becomes clear that children are not immune to the harmful effects of hostility displayed in social media and political discourse. Socio-cognitive attitudes such as Right-wing authoritarianism - primarily studied in adults - may help explain the complex cognitive pr ocesses involved in bullying among adolescents. In order to gain a richer understanding of bullying behaviors, the first purpose of this study was to examine the effect of Right-wing authoritarian attitudes on adolescent bullying behavior.

Importantly, one's victim status may also play a role in teen bullying behavior. Previous research has found a reciprocal relationship between Right-wing authoritarianism and a dangerous worldview among adults (Sibley, Wilson, \& Duckitt, 2007), indicating that those who endorse Right-wing authoritarian attitudes may have a greater propensity to feel threatened or victimized. Unsurprisingly, individuals who feel threatened may act defensively in a way to 'combat' this perceived threat. As such, teens who endorse Right-wing authoritarian attitudes may be more likely to feel aggrieved and, ultimately, bully others in response. A second purpose 
of this study was to determine whether one's sense of victimization would mediate the effect of RWA on teen self-reported bullying behavior.

Moral disengagement, another socio-cognitive attitude, may also play a key role in the perpetration of bullying. Moral disengagement describes one's propensity to morally distance themselves from an inhumane act through various cognitive processes (Bandura, 1999). Individuals may engage in cognitive processes that allow them to view their immoral actions as acceptable, downplay their role in the hostile act, utilize dehumanizing language that blames the victim or "waters down" the description of inhumane actions, and diffuses responsibility for the inflicted harm. Overall, those who are morally disengaged are less likely to accept personal responsibility for their harmful acts through various cognitive processes that allow them to feel their actions are justified. These cognitive processes may partially explain teen bullying behavior. Thus, the final purpose of this study was to examine whether different levels of moral disengagement would moderate the effect of RWA on bullying behavior that is indirectly explained by one's sense of victimization.

Two hundred-twelve $9^{\text {th }}$-grade students from a public Midwest high school served as participants and completed the Bullying and Cyberbullying Scale for Adolescents (BCS-A; Thomas, Scott, Coates, \& Connor, 2019), the RWA Scale (Altemeyer, 1981), and the Moral Disengagement Scale (MDS; Bandura et al., 1996) during their high school study hall period. Driven by the mediation model proposed by Baron and Kenny (1986) and using PROCESS procedures (Hayes, 2017), the current study utilized a moderated mediation model to examine these data.

Overall, male students scored higher than female students on the measure of RWA. No other gender effects were found. Self-reported bullying perpetration was highly correlated with 
self-reported victimization, indicating that those who admitted to bullying others also tended to feel victimized themselves. Further, Right-wing authoritarianism was associated with perceived victimization when moral disengagement was high, indicating that Right-wing authoritarian attitudes may lead to a greater propensity to feel victimized among teens who tend to justify harmful acts through cognitive processes. This sense of aggrievement may lead teens to engage in defensive, aggressive responses, thus potentially partially explaining bullying behavior. Indeed, results demonstrated that victimization, Right-wing authoritarianism, and moral disengagement all significantly impacted self-reported bullying perpetration. The indirect effect of Right-wing authoritarianism on bullying perpetration through victimization differed based on teens' levels of moral disengagement, such that for teens who engaged in the most cognitive restructuring of harmful behavior, their Right-wing authoritarian attitudes were significantly associated with increased perceived victimization and, in turn, increased bullying behavior. In addition to the indirect relation between Right-wing authoritarianism and bullying behaviors through victimization, moral disengagement also significantly moderated the direct relation between Right-wing authoritarianism and bullying behaviors, such that teens' Right-wing authoritarian attitudes were only associated with increased bullying of peers when they also reported a greater propensity to engage in cognitive processes that justify their harmful behavior.

The current study provided novel evidence suggesting the existence of Right-wing authoritarianism - a socio-cognitive attitude primarily studied in adults - in the adolescent population. Further, the current study examined moral disengagement - a socio-cognitive attitude repeatedly associated with bullying - and its relation to Right-wing authoritarianism and victimization. Importantly, Right-wing authoritarianism, when paired with high moral disengagement, led to a greater propensity to feel victimized, thus resulting in a more robust self- 
report of bullying behavior. Notably, teens in the current study responded in ways consistent with the adult social psychology and political science literature, indicating that adolescents are capable of believing in and acting on such ideologies. Understanding the relationship between socio-cognitive attitudes and bullying behavior will assist schools in implementing evidencebased curricular programming aimed at addressing bullying. Further, the current study demonstrated that adolescents are not immune to the harmful discourse rampant on various media platforms, indicating that media influence on teen attitudes should be taken into account when creating and implementing anti-bullying approaches. Hostile political discourse may influence youth and adults alike, and harmful messages have real-world implications by encouraging and exacerbating problematic tribal attitudes and behaviors. A richer understanding of socio-cognitive attitudes and their relation to behavior is crucial in addressing the rampant harassment and abuse seen on a global scale. 


\section{CHAPTER II: REVIEW OF THE LITERATURE}

\section{Bullying}

Bullying is not a new occurrence within the schools. Bullying is a widespread and complex public health epidemic that affects virtually every school. There is an abundance of research on the prevalence of bullying in schools, with the National Center for Education Statistics (2019) reporting that about $20 \%$ of students between the ages of 12 and 18 years old had been bullied at school during the 2017 school year. Consistent with these findings, the Centers for Disease Control and Prevention (CDC, 2018) found that about 19\% of students nationwide in grades 9-12 indicated that they were bullied at school within the last year. Statistics from the U.S. Department of Education, too, yield similar prevalence rates of bullying. In 2016, 25.9\% of middle-school students reported being bullied at school (U.S. Department of Education, 2016). In terms of bullying perpetration, 30\% of students admit to having bullied others in surveys (Bradshaw, Sawyer, \& O’Brennan, 2007).

Bullying does not fit into one simple category; rather, there are various avenues through which bullying can occur. Individuals can be bullied physically (e.g., being hit, kicked, pinched, spit upon, tripped, pushed; having personal property stolen or destroyed), verbally (e.g., being threatened, teased, or called names; having inappropriate comments directed toward them), or relationally (e.g., being left out of an activity on purpose; having others be told not to be friends with them; having lies or rumors spread about them; or being embarrassed publicly) (Crick \& Grotpeter, 1995; Evans, Frazer, Blossom, \& Fite, 2019; U.S. Department of Health and Human Services, 2019; Williams \& Guerra, 2007).

Bullying also does not necessarily stop when students leave school grounds. With society's rapidly expanding technological advances, novel avenues for bullying have appeared. 
Social media websites, texting, and various phone applications allow for near-constant access to social communication. Because children and adolescents have a greater access than ever before to technology such as smart phones, tablets, and laptops, bullying can occur at virtually any time of the day online. Bullying that occurs digitally is referred to as cyberbullying (U.S. Department of Health and Human Services, 2019). Cyberbullies may publicly post a mean or offensive picture or status in an attempt to hurt another person. Or, one might send a direct message through an app or game with threats or insults. There are various avenues through which cyberbullying can occur, and schools must keep up with them to implement informed bullying prevention and intervention curriculum. The National Center for Education Statistics (2019) reported that about $15 \%$ of students between the ages of 12 and 18 years reported being cyberbullied within the last year. Similarly, the CDC (2018) indicated similar findings, with $14.9 \%$ of students surveyed reporting having been cyberbullied within the last year. Thus, cyberbullying poses a real and alarming problem as technology continues to advance. It should be noted, too, that victims of cyberbullying are rarely victimized solely online; rather, they tend to be victimized in person, as well (Salmivalli, Sainio, \& Hodges, 2013).

Research indicates that in addition to the different forms of bullying, there are different types of bullies. Consequently, bullying may serve diverse functions for the various types of bullies. First, there is the pure bully who perpetrates instrumental aggression. Instrumental aggression, or proactive aggression, is more calculated and often functions as a means to obtaining a goal or reward (Card \& Little, 2006; Dodge, Lochman, Harnish, Bates, \& Pettit, 1997; Raine et al., 2006). This type of bullying is often characterized by its deliberate, seemingly "cold-blooded" approach to personal gain. Pure bullies may act aggressively toward other students, for example, in an attempt to gain increased social status or popularity. Bullying 
perpetration has been associated with more favorable social status and, interestingly, has not been associated with significant social problems, at least in the short-term (Evans, Frazer, Blossom, \& Fite, 2019; Reijntjes et al., 2013). Thus, due to minimal immediate, negative repercussions for their bullying, bullies tend to believe they are gaining more than they are losing through bullying and find it an effective way to increase instrumental benefit. These types of bullies are purely perpetrators - they are not victimized themselves and often are equally integrated into the school social network despite their harassment of others (Veenstra et al., 2005).

Bully-victims, in contrast to pure bullies, tend to be easily provoked and perpetrate reactive aggression. Reactive aggression tends to be an emotionally charged, defensive response to perceived provocation (Card \& Little, 2006; Dodge, Lochman, Harnish, Bates, \& Pettit, 1997; Raine et al., 2006). Bully-victims, unlike bullies, tend to be less liked by peers and tend to exhibit more internalizing problems, more emotional dysregulation and ADHD symptoms, and less prosocial behavior (Card \& Little, 2006; Evans, Frazer, Blossom, \& Fite, 2019; Veenstra et al., 2005). Thus, discernible differences exist between those who bully and versus those who are not victimized themselves in terms of potential functions behind their bullying behaviors.

Short- and long-term negative effects of bullying victimization are well-documented (Holt \& Espelage, 2007; Kvarme, Helseth, Sæteren, \& Natvig, 2010; Nansel et al., 2001; Solomontos-Kountouri, Tsagkaridis, Gradinger, \& Strohmeier, 2017; Wolke, Copeland, Angold, \& Costello, 2013; Wolke \& Lereya, 2015), and perpetrators of bullying are not immune to its harmful effects (Nansel et al., 2001; Reijntjes et al., 2013; Scholte et al., 2007; SolomontosKountouri, Tsagkaridis, Gradinger, \& Strohmeier, 2017; Stefanek, Strohmeier, \& Yanagida, 2017; Veenstra et al., 2005). Further, those who are both perpetrators and victims of bullying 
(called "bully-victims") experience a host of negative outcomes. Being both a perpetrator and victim of bullying has been associated with poorer academic achievement and school functioning, lower levels of school liking, and has also been associated with loneliness and poor peer relationships (Haynie et al., 2001; Nansel et al., 2001; Stefanek, Strohmeier, \& Yanagida, 2017). Bully-victims, when compared to pure bullies and purer victims, also exhibit the worst health outcomes in adulthood, being more likely to be diagnosed with a serious medical or psychiatric illness, to engage in regular smoking, and to be slow in recovering from illness (Wolke, Copeland, Angold, \& Costello, 2013). Further, their levels of optimal psychosocial functioning are the lowest, and they are more likely to display problem behaviors, depressive symptoms, and lower self-control and social competence (Haynie et al., 2001; Stefanek, Strohmeier, \& Yanagida, 2017). As previously indicated, bully-victims also tend to be the most disliked by peers compared to bullies and victims (Veenstra et al., 2005). Thus, individuals who are both perpetrators and victims of bullying are at a higher risk of negative psychological and physical outcomes. It is imperative, then, that school personnel, parents, and researchers alike gain a better understanding of bully-victims to better prepare bullying intervention and preventative measures. Gaining a deeper understanding of the connection between victimization and perpetration - the co-occurrence of the two - can better prepare communities to combat bullying and provide support to students. Thus, a purpose of the current study was to analyze how the co-occurrence of bullying and victimization interact play an explanatory role in reported perpetration.

Whereas bullying - and the harmful effects of bullying - have been noted for decades, the concurrent increase in bullying incidences in the schools and increasingly polemic rhetoric in the media are alarming. Thus, it becomes apparent that children are not immune to the harmful 
impacts of hostility displayed in social media and political discourse. However, while negative effects of broadcasted harassment are clear, little is known about the harassing socio-cognitive attitudes that may drive children's bullying behavior.

\section{Right-Wing Authoritarianism}

Researchers and clinicians have long recognized that bullying behavior may depend on individual differences in socio-cognitive processes in children (Crick \& Dodge, 1999; Ziv, Leiovich, \& Shechtman, 2013). One socio-cognitive attitude that may be of particular explanatory importance to bullying is one that is currently also prevalent in the political realm: right-wing authoritarianism (RWA).

Right-wing authoritarianism has been less studied among children compared to adults; however, evidence exists indicating that ideologies such as RWA can be transmitted intergenerationally. Children of authoritarian fathers are more likely to associate with bullies or be bullies and are less likely to accept members of an 'out-group' (Baldry \& Farrington, 2000; Knafo, 2003). Further, intergenerational similarities have been observed in the prejudices associated with RWA and social dominance orientation (SDO; Duriez \& Soenens, 2009). In other words, children of parents with prejudiced dispositions rooted in RWA and SDO ideology tend to hold the same beliefs. Thus, children and adolescents are capable of believing in and acting on these ideologies, and the adult political science and social psychological bodies of research on maladaptive conservative ideology may help clarify some of these unexplored sociocognitive attitudes of child bullies.

Notably, individuals who score high in RWA tend to classify people into an "in-group" or "out-group," and those who are in the "out-group" are viewed as threatening and dangerous to the values of the "in-group" (Beck \& Plant, 2018; Whitley, 1999). In terms of bullying and 
harassment, individuals high in RWA may view their victims as members of an "out-group" who threaten their values that may lead to more open cruelty. This cruelty might be perceived as justified to those high in RWA, as those in the "out-group" tend to be perceived as 'less than' the group to which the bully belongs.

Right-wing authoritarianism, then, tends to become associated with prejudice, discrimination, and hostility toward individuals not directly in one's "in-group" (Duckitt \& Sibley, 2007; Crawford, Brandt, Inbar, \& Mallinas, 2016; McCullough, Dispenza, Chang, \& Zeligman, 2019; Whitley, 1999). A meta-analysis conducted by Jost, Kruglanski, and Sulloway (2003) connected RWA attitudes with support for increased severity of punishment for those who break the law, racial prejudice, homophobia, and victim blaming, as well as opposition to issues such as environmentalism, abortion rights, and services for individuals with AIDS or who are homeless. Further, those high in RWA view themselves as morally superior to those who do not share their traditional values, and they are more likely to blatantly express prejudice against groups with different values (Whitely, 1999).

Perceptions of security of the in-group plays an important role in RWA, as well.

Individuals who view the world as a more dangerous or threatening place tend to score higher on RWA (Sibley, Wilson, \& Duckitt, 2007). Curiously, Sibley, Wilson, and Duckitt (2007), in their longitudinal study, found a reciprocal relationship between RWA and dangerous worldview, such that not only did a dangerous worldview predict higher RWA, but higher RWA endorsement later predicted a dangerous worldview, as well. Similarly, those who are high in RWA are more likely to support policies that may negatively impact marginalized immigrants if the policies would be implemented in their home country versus another country, thus highlighting the motivating role of security against "out-groups" (Craig \& Richeson, 2014). As 
such, individuals high in RWA may be more likely to feel threatened or victimized and may act in ways to 'combat' this threat.

Importantly - and alarmingly - as current political discourse grows increasingly hostile, individuals may feel empowered to act in accordance with the hostile messages of those in authority (Beck \& Plant, 2018). Coincidentally, if RWA is present in children and/or adolescents, the hateful rhetoric displayed by those in political power may empower them to mistreat others. Thus, another purpose of the current study was to examine the effect of RWA on adolescent bullying behaviors.

Further, as discussed above, victim status may also play a role in bullying behavior. Individuals who perceive that they have been victimized may, in turn, victimize others. As such, victim status may partially explain the relationship between RWA and bullying behaviors. Individuals higher in RWA may have a greater sense of victimization; in other words, those who endorse RWA may be more likely to report feeling victimized or threatened in some capacity. Indeed, it is easy to imagine why those who more likely feel we live in threatening circumstances - especially because of those "dangerous others" unlike ourselves - might have greater propensity to feel victimized. Thus, as described by the seminal work of Dodge (1980), a hostile attribution bias (i.e., "I must infer hostile intentions from others"; "everyone is out to get me") becomes a credible explanation of antisocial and entitled social behavior, especially bullying.

In order to gain a more complex understanding of bullying behaviors, this study aimed to examine the connection between RWA, victimization, and bullying behaviors. In other words, this study sought to determine whether victimization status mediates the effect of RWA on teen self-reported bullying behaviors. 


\section{Moral Disengagement}

The relationship between RWA, victimization, and bullying behaviors may not be the same for all children, however. Another socio-cognitive variable may also explain the association between these constructs: moral disengagement. Simply put, moral disengagement is a way for individuals to justify or rationalize their destructive behavior. Moral disengagement is the mechanism through which individuals can distance themselves from moral standards and self-sanctions when committing harmful acts (Bandura, 1999). In other words, the process of morally disengaging allows perpetrators to separate themselves from their harmful actions which, in turn, alleviates distress that perpetrators might otherwise feel due to the incongruence between their actions and one's values and moral code.

Moral disengagement can occur through various avenues. Individuals who are morally disengaged may reframe their immoral actions as moral or they may downplay their role in a hostile act (Bandura, 1999). For example, currently in the U.S., some individuals have argued that it is not wrong to place children and families in migrant detention centers (centers whose inhumane conditions are infamous) if the families did not enter the country legally. One might interpret this as a means of moral disengagement: through this logic, individuals are framing the inhumane treatment of other human beings as moral and just "because we need to protect the border."

Through another avenue of moral disengagement, perpetrators may use language that dehumanizes and blames their victims in an attempt to justify their actions (Bandura, 1999). Stripping humanity away from victims and blaming victims for the atrocities inflicted upon them rids perpetrators of any personal responsibility. In reference to one of the United States' most controversial topics, immigration, president Donald Trump has been recorded referring to certain 
groups of immigrants as "animals" and has pushed a narrative that paints immigrants as dangerous criminals. This tactic can likely be observed in bullying, as well. Bullies tend to claim that their victims "deserved it" for one reason or another or may view them as "less than." These harmful attitudes, unsurprisingly, can lead to inhumane treatment of others.

Moral disengagement might also occur through the use of euphemistic labeling, according to Bandura (1999). Euphemistic labeling essentially involves the 'watering down' of the way in which inhumane actions are described. By lessening the severity of the language used to describe inhumane actions, the actions themselves are depicted as less harmful. In relation to bullying, one might euphemistically label verbal bullying as "teasing" in an attempt to lessen the severity of the situation and absolve themselves of personal blame.

Individuals who are morally disengaged may also attempt to absolve themselves through the diffusion of responsibility among other individuals involved in the inhumane acts (Bandura, 1999). Those who are morally disengaged may feel that atrocities committed in a group cannot lead to individual attribution of blame. Similarly, the fact that bullying involves not only the bully and victim, but surrounding peers (i.e., bystanders) as well, is widely accepted as diffusion of responsibility in the bullying literature (Salmivalli, Lagerspetz, Björkqvist, Österman, \& Kaukiainen, 1996; Salmivalli, Voeten, \& Poskiparta, 2011). Higher levels of moral disengagement are known to be associated with bullying perpetration and certain bystander behavior (Obermann, 2011; Runions et al., 2019).

Overall, those who are more morally disengaged are less likely to accept personal responsibility for harmful acts through various avenues of cognitive restructuring. This restructuring allows individuals to engage in morally inhumane acts without feeling that they themselves are immoral. Thus, it becomes clear that increased moral disengagement can lead act 
aggressive and harmful acts toward others. Individuals who are morally disengaged may be less averse to inflicting harm upon others through bullying. Although debate still remains due to some inconsistent findings, moral disengagement likely contributes to cyberbullying in addition to traditional bullying (Bussey, Fitzpatrick, \& Raman, 2015; Perren \& Gutzwiller-Helfenfinger, 2012; Pornari \& Wood, 2010; Robson \& Witenberg, 2013; Runions \& Bak, 2015). Moral disengagement, then, may play a critical role in the process of bullying. Thus, another purpose of the current study was to examine whether different levels of moral disengagement moderate the effect of RWA on bullying behavior that is indirectly mediated by one's sense of victimization.

\section{Overview of the Present Study}

Utilizing archival data collected in the fall of 2019 , the current study aimed to better examine the relations among RWA, moral disengagement, and victim experiences as they pertain to the explanation of self-reported bullying behavior among $9^{\text {th }}$ graders attending a public high school. In particular, this study examined whether self-reported victim status serves a mediating role in the relationship between RWA and self-reported bullying behavior. Further, the current study examined whether this mediation model changes as a function of $9^{\text {th }}$-graders level of moral disengagement. In other words, this study sought to determine whether moral disengagement serves as a moderator for the indirect relationship between RWA and bullying behavior involving victim status. Lastly, the moderating effect of moral disengagement on the direct relationship between RWA and bullying behavior was examined. Thus, this study's were as follows:

1) Does the co-occurrence of bullying and victimization play an explanatory role in selfreported perpetration?

2) What is the effect of RWA on adolescent self-reported bullying behavior? 
3) Does victimization status mediate the effect of RWA on teen self-reported bullying behavior? (see Figure 1 below)

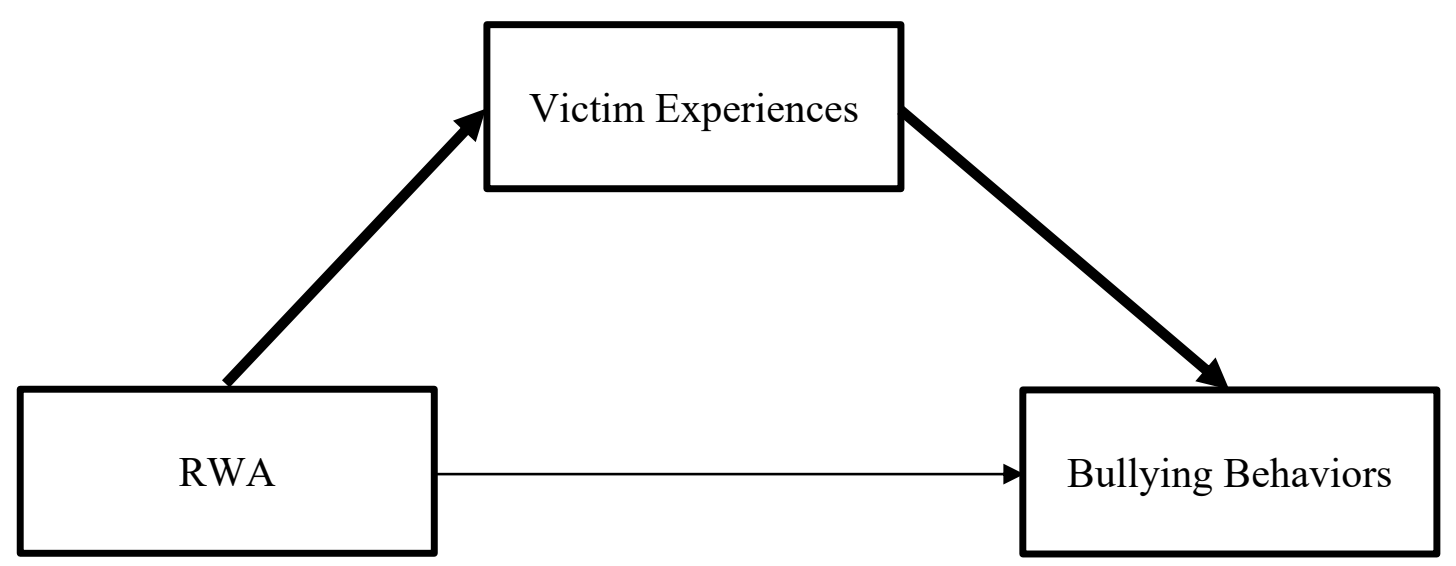

Figure 1. Hypothesized mediation model wherein perceived victim experiences mediate the relationship between RWA and self-reported bullying behaviors.

4) Do different levels of moral disengagement moderate the effect of RWA on self-reported bullying behavior that is indirectly mediated by one's sense of victimization? (see Figure 2 below) 


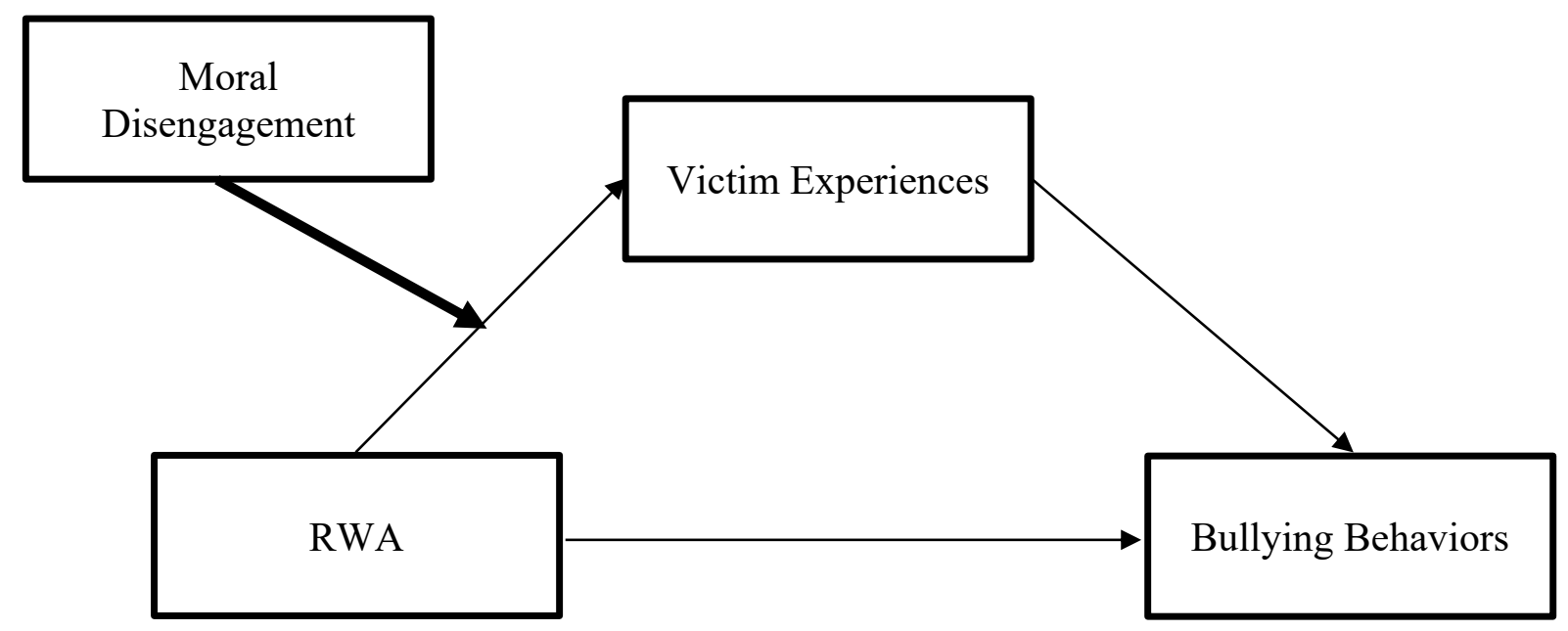

Figure 2. Hypothesized moderated mediation model wherein moral disengagement moderates the effect of RWA on self-reported bullying behavior that is indirectly mediated by one's sense of victimization.

5) Do different levels of moral disengagement moderate the direct effect of RWA on selfreported bullying behavior? (see Figure 3 below) 


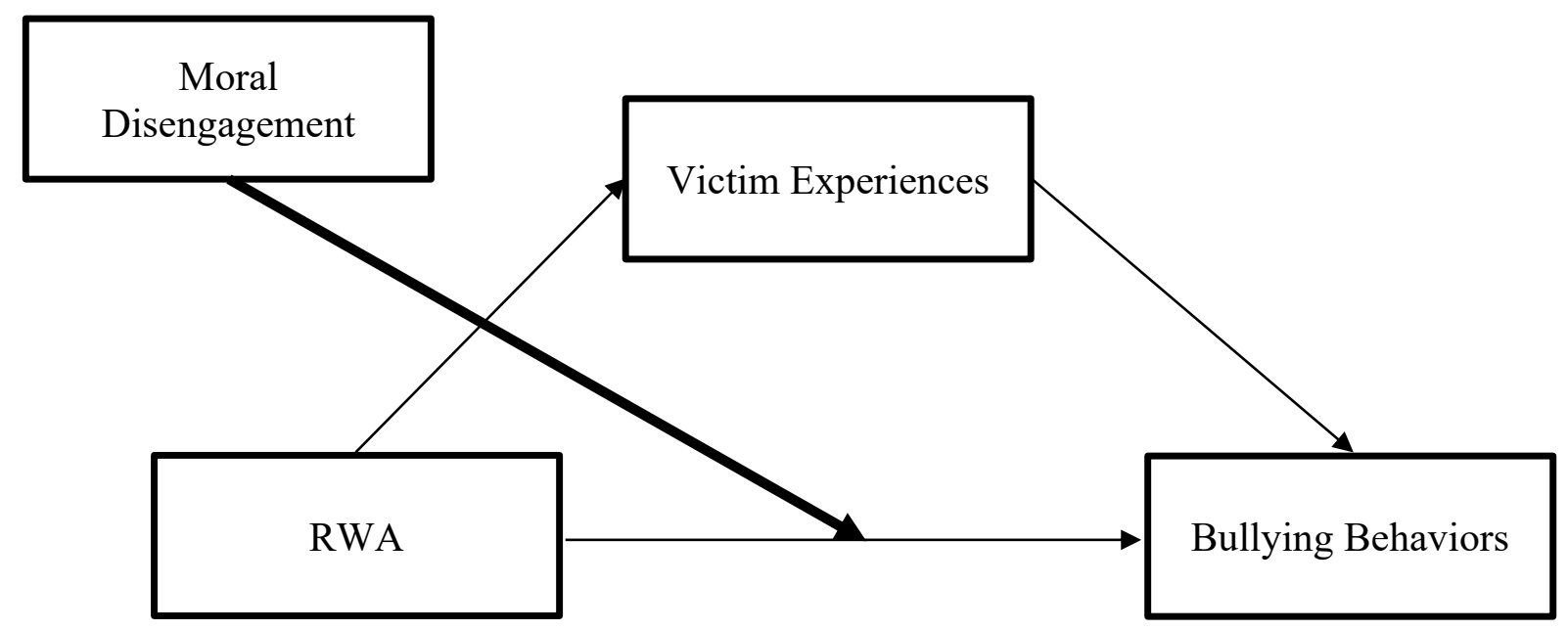

Figure 3. Hypothesized moderated mediation model wherein moral disengagement moderates the direct effect of RWA on self-reported bullying behaviors. 


\section{CHAPTER III: METHOD}

\section{Participants}

Participants were 212 9th-grade students (106 males, 92 females, 14 unspecified) from a public Midwest high school. About $42.7 \%$ of the total $9^{\text {th }}$-grade population at the school participated in the study. Seventy-eight of the original 290 participants were excluded from analyses due to incomplete scales or comments typed within the demographic information section that potentially indicated that certain participants were not responding in a serious manner. For example, the demographic information section prompted students to indicate their gender identity and provided an option to select "Other" and type in their gender identity should it not already be listed. Some students wrote in responses that did not reflect gender identities.

According to the Illinois State Board of Education in 2019 (2019), 56\% of these students were White, $28.6 \%$ of students were two or more races, $10.9 \%$ of students were Asian, $3.9 \%$ of students were Hispanic, $0.3 \%$ of students were Black, $0.1 \%$ of students were American Indian, and $0.1 \%$ of students were Pacific Islander. Further, $4.8 \%$ of students at this school were classified as low income, $1.1 \%$ of students were English learners, and $0.2 \%$ of students were homeless in 2019. The Illinois State Board of Education (2019) also indicated that $14 \%$ of students at this high school were being served by individual educational plans (IEPs).

\section{Measures}

Bullying and Cyberbullying Scale for Adolescents (BCS-A)

Self-reported bullying perpetration and victimization online and offline were measured using a slightly altered Bullying and Cyberbullying Scale for Adolescents (BCS-A; Thomas, Scott, Coates, \& Connor, 2019). This version of the BCS-A contains 28 items about which participants indicate the frequency of certain aggressive behaviors that have been done to them 
or that they have done within the last month on a 4-point Likert scale (never, once or twice, several times, a lot of times). The BCS-A measures bullying perpetration and victimization. In particular, the scale assesses online bullying perpetration (e.g. "sent or posted mean or hurtful pictures/videos about someone"), online bullying victimization (e.g. "sent or posted mean or hurtful pictures/videos about me"), offline bullying perpetration (e.g. "punched, hit, kicked, pushed or shoved someone, on purpose," "spread false rumors about a person to hurt them or make others not like them"), and offline bullying victimization (e.g. "damaged, hid, or stole my belongings, on purpose," "left me out of a group or activity, or did not allow me to join in, on purpose"; see Appendix A). For this sample, there was excellent internal consistency for both the bullying perpetration $(\alpha=.92)$ and victimization $(\alpha=.93)$ scale.

\section{Right-Wing Authoritarianism Scale (RWA Scale)}

Right-wing authoritarianism was measured using an adapted version of Altemeyer's (1981) RWA Scale (e.g., "Our country will be great if we do what the authorities tell us to do and we ignore those who disagree with authority”). This 18-item scale assesses an individuals' submission to authority figures, conventionalism, and tendency to engage in aggression endorsed by authority figures (Altemeyer, 1981). Items were adapted to meet the developmental level of 9th-grade students such that items endorsing illegal activities were removed, and item language was "watered down" to make the scale more appropriate for a school setting (see Appendix B). The $R W A$ Scale for this sample yielded good internal consistency $(\alpha=.86)$. Moral Disengagement Scale (MDS)

An abbreviated 24-item version of the Moral Disengagement Scale (Bandura et al., 1996; $M D S$; e.g., "Kids who get mistreated usually do things that deserve it") was administered to assess the tendency students have to distance themselves from immoral behavior (see Appendix 
C). Bandura et al. (1996) report evidence of adequate reliability, and the scale yielded excellent internal consistency for this sample $(\alpha=.90)$.

\section{Procedure}

Prior to implementation of all study procedures, this study was approved by the Institutional Review Board (IRB) of Illinois State University. At least five business days prior to the administration of the surveys, parents and caregivers of 9th-grade students at a Midwest high school were informed of the date and nature of the study via school email. Parents/caregivers were instructed to contact the primary researcher should they choose to opt their child out of the study; all 9th-grade students whose parents/caregivers did not contact the primary researcher were considered eligible for participation. As students only have one study hall period per week, students completed the survey on the day of the week their study hall occurred on (as was school preference). Thus, students took the survey at different times on different days within the same week period.

Homeroom and study hall supervisors were informed of the study and given instructions on how to present the study and answer questions that might have arisen. Study hall supervisors were also given a list of students whose parents/guardians had opted them out of the study, and the supervisors discretely informed these students to refrain from completing the survey.

Before initiation of the survey, each student read an assent letter informing him/her/them of the nature of the study, emphasizing the voluntary nature of the study, and ensuring anonymity. Students who assented to the study were then prompted to create a unique, anonymous ID. Participants were instructed to create their ID by typing the first digit of their home address, the first two letters of their mother's first name, and the last two digits of their phone number. Participants were provided instructions and an example of how to create this ID. 
After creating their ID, participants completed the measures in counter-balanced order as part of a comprehensive Qualtrics survey. Participants completed the surveys during a study hall or homeroom period on their school-provided Google Chromebooks. Study hall and homeroom periods last about 45 minutes each day; thus, students were expected to have ample time to complete the measures to the best of their ability. At the end of the survey, students were asked to indicate the type of device on which they completed the survey (i.e., laptop, cell phone, tablet). Although students were encouraged to complete the survey on their school-administered laptops, these device-related data were collected in order to determine whether type of device used had a differential effect on completion rates of the survey.

After completion of the measures, students were allowed to resume other schoolwork for any remaining time in study hall. Once the class period ended, participants were thanked for their involvement in the study. All responses from these $9^{\text {th }}$ grader students were consolidated to form a data archive for subsequent analysis.

\section{Analytic Approach}

Data analysis was driven by the mediation design described by Baron and Kenny (1986). In this model, the association between RWA (the predictor variable) and self-reported bullying (the criterion variable) were examined. Further, the relationship between RWA and self-reported victim experiences (the potential mediator) were examined. These analyses addressed the following research question: what is the effect of RWA on adolescent self-reported bullying behavior? Then, the mediating role of victimization in the explanation of RWA effects on bulling was examined (see Figure 1). Analyses addressed the following research question: does victimization status mediate the effect of RWA on teen self-reported bullying behavior? Additionally, $9^{\text {th }}$ graders' level of moral disengagement was also examined as a potential 
moderator of the mediating effect of self-reported victim experiences in explaining how RWA effects bullying behavior (Baron \& Kenny, 1986; Holmbeck, 1997; see Figure 2). In other words, this study sought to determine whether the explanatory association among RWA, self-reported victim experiences, and bullying behaviors varies as a function of teens' level of moral disengagement. These analyses addressed the following research question: do different levels of moral disengagement moderate the effect of RWA on self-reported bullying behavior that is indirectly mediated by one's sense of victimization? Finally, $9^{\text {th }}$ graders' level of moral disengagement was examined as a potential moderator of the direct relation between RWA and bullying behaviors (see Figure 3). These analyses addressed the final research question: do different levels of moral disengagement moderate the direct effect of RWA on self-reported bullying behavior? Thus, to examine these research questions, the current study utilized a moderated mediation model. 


\section{CHAPTER IV: RESULTS}

\section{Descriptive Analyses}

Two hundred ninety students began the survey. The final sample of students who provided responses to all variables of interest (victimization, perpetration, RWA, and moral disengagement) was 212 students. Means, standard deviations, and zero-order correlations are presented in Table 1.

Table 1

Means, Standard Deviations, and Zero-Order Correlations of Study Measures $(\mathrm{N}=212)$

\begin{tabular}{lcccc}
\hline Variables & 1 & 2 & 3 & 4 \\
\hline 1. Victim & - & $.66^{* *}$ & $.18^{*}$ & $.20^{* *}$ \\
2. Perp & & - & $.33^{* *}$ & $.36^{* *}$ \\
3. RWA & & & - & $.25^{* *}$ \\
4. MD & & & & - \\
$M$ & 1.45 & 1.19 & 1.99 & 2.14 \\
$S D$ & 0.55 & 0.34 & 0.45 & 0.38 \\
\hline
\end{tabular}

Note. Victim = self-reported victim experiences; Perp = self-reported bullying perpetration; $\mathrm{RWA}=$ Right-wing authoritarianism; $\mathrm{MD}=$ moral disengagement. $* p<.05$. ${ }^{* *} p<.01$.

As shown in Table 1, bullying victimization and perpetration were highly correlated. In other words, students in this sample who self-reported bullying behavior were also more likely to report feeling victimized. Further, victimization was associated with both RWA and moral disengagement. Self-reported bullying perpetration was highly correlated with both RWA and moral disengagement. Lastly, RWA and MD were highly correlated with each other.

Analyses were run to assess the presence of gender effects. In particular, independent samples $t$-tests were run to examine whether differences existed in the self-reporting of RWA, moral disengagement, and bullying involvement between male and female students. Only one of these tests yielded statistical significance. Overall, male students $(M=2.10, S D=.42)$ scored 
higher than female students $(M=1.85, S D=.35)$ on the measure of $\mathrm{RWA}, p<.001,95 \% \mathrm{CI}=$ $[0.15,0.36]$. No other gender effects were noted.

\section{Main Analyses}

Research questions regarding potential mediating and moderating effects were examined utilizing PROCESS procedures (see Figure 4; Hayes, 2017; see Figures 4 and 5).

\section{Conceptual Diagram}

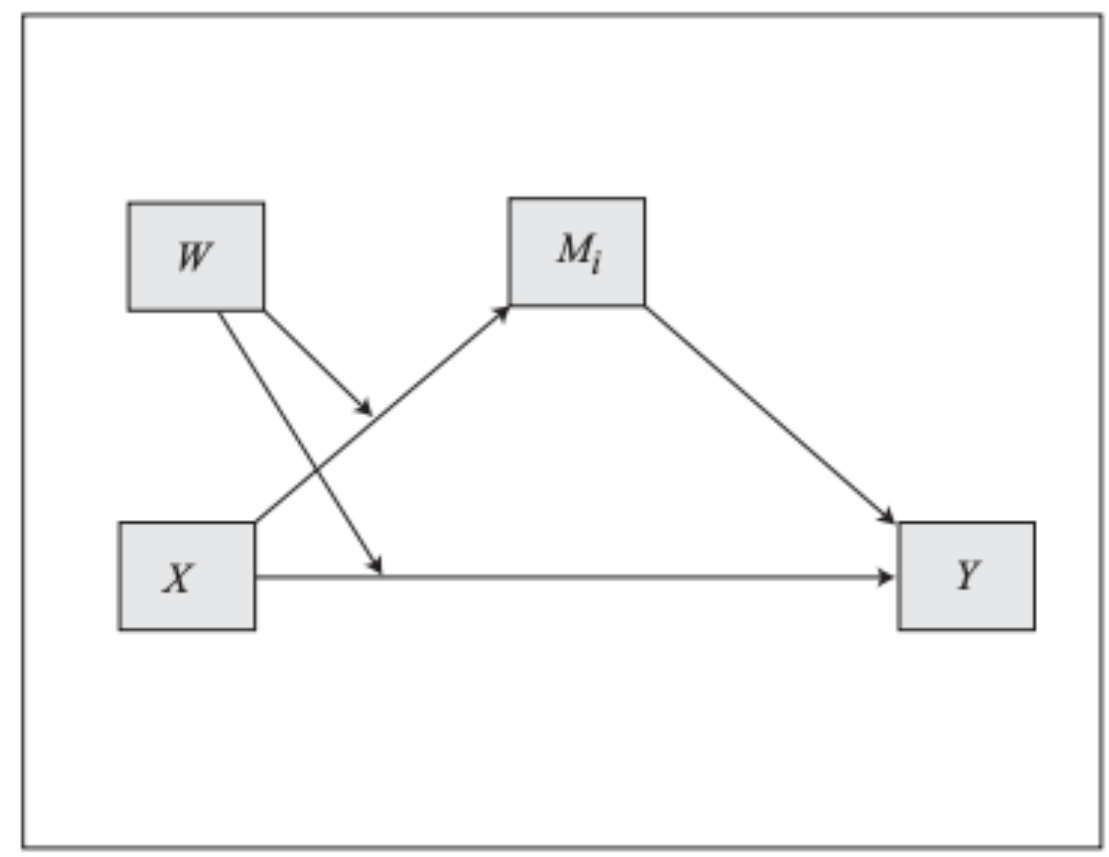

Figure 4. PROCESS Model 8 Conceptual Diagram (Hayes, 2017) 


\section{Statistical Diagram}

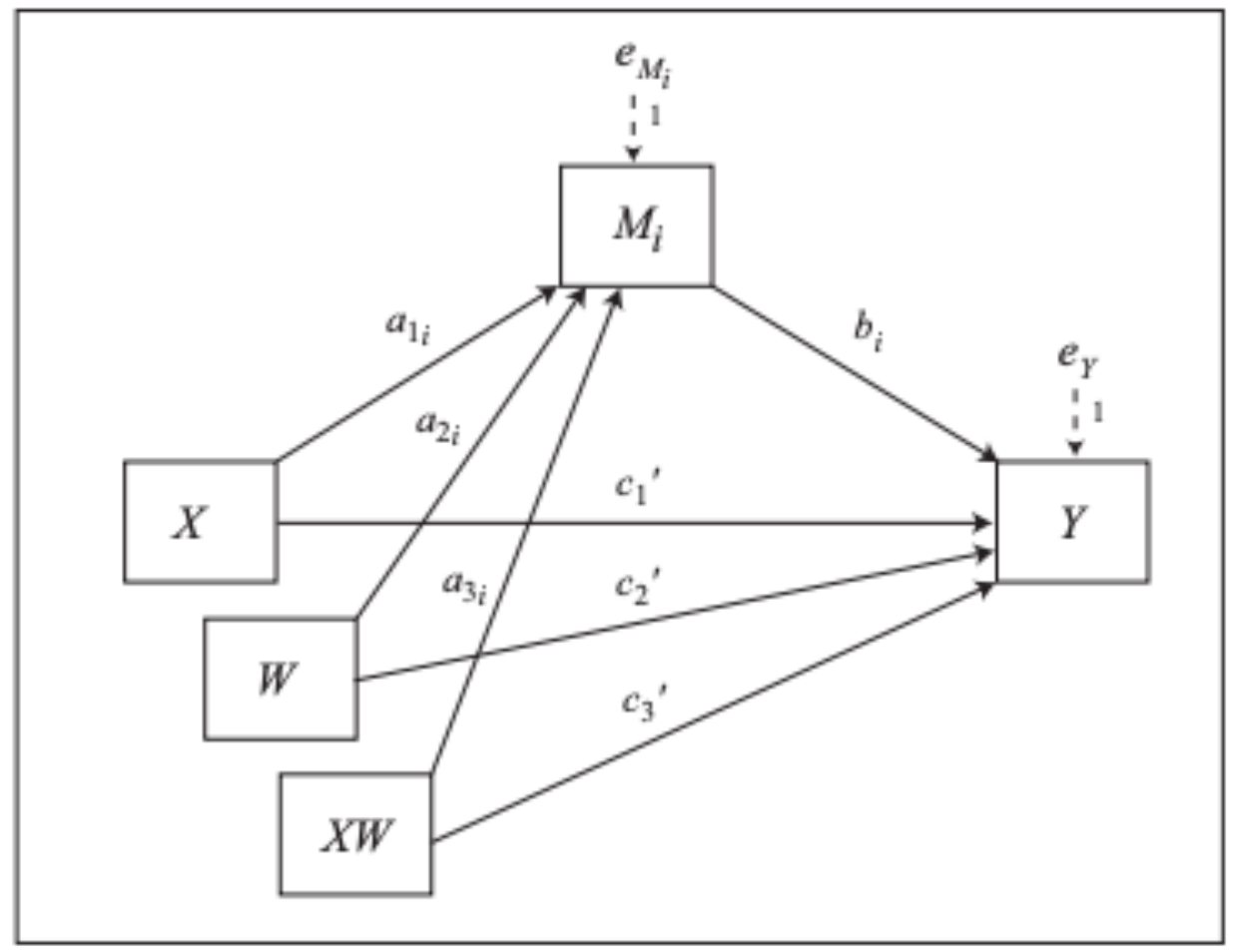

Conditional indirect effect of $X$ on $Y$ through $M_{i}=\left(a_{1 i}+a_{3 i} W\right) b_{i}$

Conditional direct effect of $X$ on $Y=c_{1}{ }^{\prime}+c_{3}{ }^{\prime} W$

•Model 8 allows up to 10 mediators operating in parallel

Figure 5. PROCESS Model 8 Statistical Diagram (Hayes, 2017)

All continuous variables were standardized to reduce skew and increase interpretability.

First, results indicated a statistically significant regression model predicting victim experiences, $\left.F(3,208)=11.17, R^{2}=.14, p<.001\right) . \operatorname{RWA}(\beta=0.10, p=.162,95 \% \mathrm{CI}=[-0.04,0.23])$ and $\operatorname{MD}(\beta=0.12, p=.11,95 \% \mathrm{CI}=[-0.03,0.27])$ did not have statistically significant effects on victim experiences; however, the interaction between RWA and MD was statistically significant $(\beta=0.26, p<.001,95 \% \mathrm{CI}=[0.14,0.38])$. 
Further, results indicated a statistically significant regression model predicting bullying perpetration, $\left.F(4,207)=63.10, R^{2}=.55, p<.001\right)$. Victim experiences $(\beta=0.52, p<.001,95 \%$ $\mathrm{CI}=[0.42,0.62]), \mathrm{RWA}(\beta=0.16, p=.002,95 \% \mathrm{CI}=[0.06,0.25])$, and moral disengagement $(\beta=0.19, p=.001,95 \% \mathrm{CI}=[0.08,0.29])$ had statistically significant effects on bullying perpetration, and the interaction between RWA and MD was statistically significant $(\beta=0.18, p$ $<.001,95 \% \mathrm{CI}=[0.09,0.27])$.

RWA's indirect effects on perpetration through victim experiences $(\beta=0.05,95 \% \mathrm{CI}=$ $[-0.01,0.13])$ was moderated by moral disengagement (Indirect Effect of Moderated Mediation, $\beta=0.14,95 \% \mathrm{CI}=[0.04,0.22])$. In particular, the indirect effect of RWA on bullying behaviors differed based on low $(\beta=-0.08,95 \% \mathrm{CI}=[-0.19,0.02])$ and high $(\beta=0.18,95 \% \mathrm{CI}=[0.05$, 0.28]) levels of moral disengagement through increased victimization. In other words, for those with a lower level of moral disengagement, there was not a statistically significant indirect effect of RWA on bullying through perceived victimization, but there was for those with a higher level of moral disengagement. Thus, RWA was only linked to perceived victimization and, in turn, bullying behaviors, when moral disengagement is high.

Moral disengagement also significantly moderated the direct relation between RWA and bullying behavior, such that RWA's direct effect on bullying behavior differed as a function of low $(\beta=-0.01, p=.906,95 \% \mathrm{CI}=[-0.14,0.13])$, mean $(\beta=0.16, p=.002,95 \% \mathrm{CI}=[0.06$, $0.25])$, and high $(\beta=0.32, p<.001,95 \% \mathrm{CI}=[0.20,0.44])$ levels of moral disengagement (see Figure 6). In other words, a higher level of moral disengagement increased the direct effect of RWA on bullying behaviors. Notably, RWA was only directly linked to bullying behavior when the level of moral disengagement was high. 


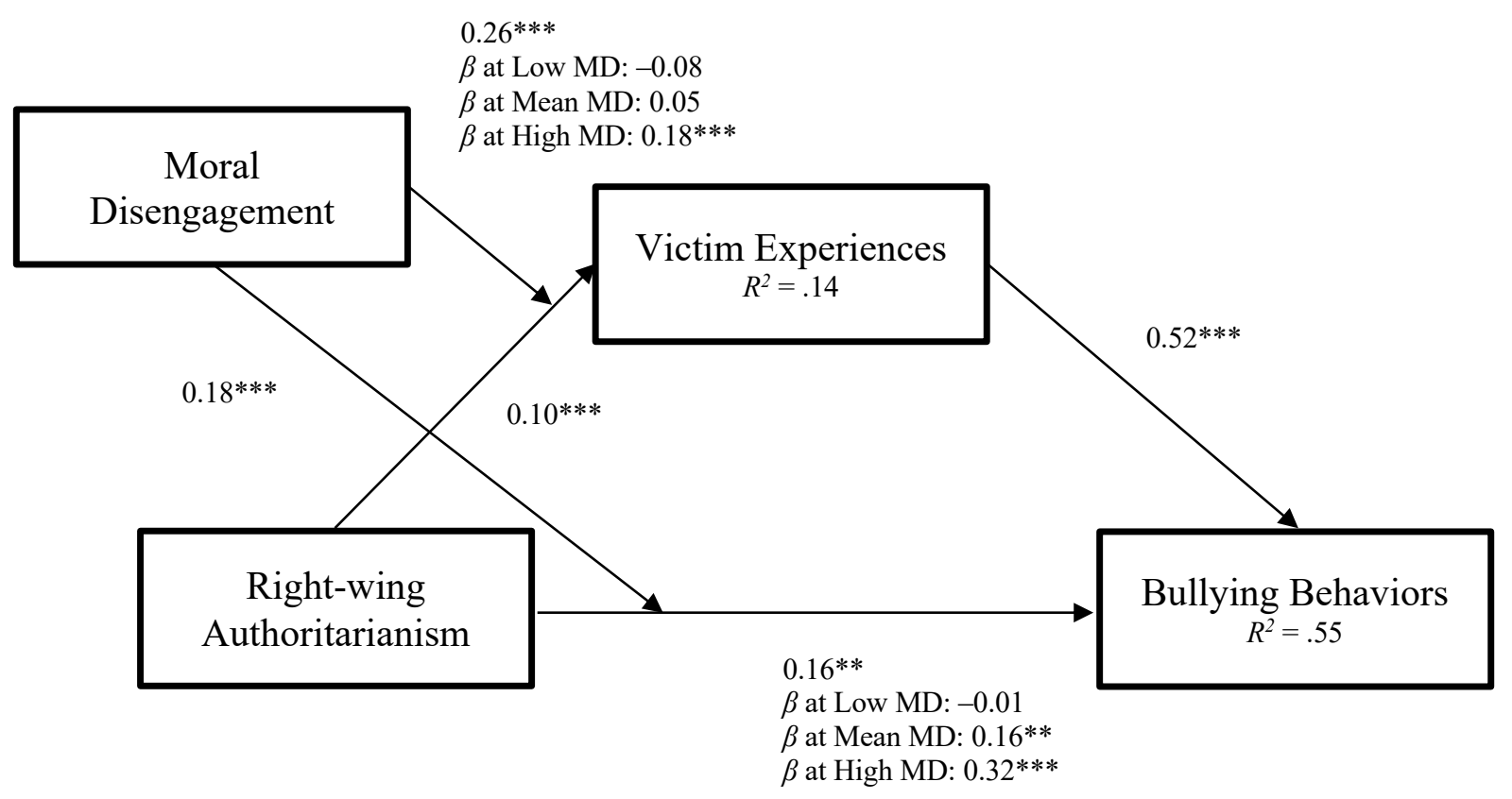

Figure 6. Moderated mediation model. ${ }^{*} p<.05 .{ }^{* *} p<.01 .{ }^{* * *} p<.001$. 


\section{CHAPTER V: DISCUSSION}

The purpose of the current study was to examine the relations among Right-wing authoritarianism (RWA), moral disengagement (MD), and sense of victimization as they pertain to the explanation of self-reported bullying behavior among $9^{\text {th }}$ graders attending a public high school. In particular, this study addressed the following research questions: (1) Does the cooccurrence of bullying and victimization play an explanatory role in self-reported bullying perpetration? (2) What is the effect of RWA on adolescent self-reported bullying behavior? (3) Does level of victimization mediate or explain the effect of RWA on teen self-reported bullying behavior? (4) Do different levels of moral disengagement moderate the effect of RWA on selfreported bullying behavior that is indirectly mediated by one's sense of victimization? (5) Do different levels of moral disengagement moderate the direct effect of RWA on self-reported bullying behavior?

Results indicated that self-reported bullying perpetration was highly correlated with selfreported victimization, suggesting that there was a high propensity for those who admitted to bullying to also feel victimized by bullying. Consistent with previous research, this was troubling, as bully-victims tend to experience a plethora of negative outcomes, often faring worse than pure bullies and pure victims (Haynie et al., 2001; Nansel et al., 2001; Stefanek, Strohmeier, \& Yanagida, 2017; Veenstra et al., 2005; Wolke, Copeland, Angold, \& Costello, 2013). Further, while neither Right-wing authoritarianism nor moral disengagement significantly impacted self-reported victimization individually, Right-wing authoritarianism was associated with perceived victimization when moral disengagement was high. In other words, Right-wing authoritarianism may lead to an increased likelihood of feeling victimized among teens who engage in the most cognitive restructuring of harmful acts. This means that teens who both align 
with Right-wing authoritarian attitudes (such as strong submission to authority figures, hostility toward members of an out-group, and high conventionality) and who are likely to distance themselves from their harmful actions are more likely to report feeling victimized. This sense of victimization may lead to a teen's defensive, aggressive response. Indeed, results indicated that victimization, Right-wing authoritarianism, and moral disengagement all significantly impacted self-reported bullying perpetration. Put altogether, indirect and direct explanatory pathways emerged.

As reported previously, the indirect effect of Right-wing authoritarianism on bullying perpetration through sense of victimization differed based on reported levels of moral disengagement. Specifically, teens' self-reported Right-wing authoritarian attitudes did not impact their feelings of being victimized and, subsequently, their bullying perpetration if their level of moral disengagement was lower. However, for teens who engage in the most cognitive restructuring of harmful behavior, their Right-wing authoritarian attitudes were significantly associated with increased perceived victimization and, in turn, increased bullying perpetration. Whether these students reporting victimization were truly being harassed is unknown; however, a greater propensity to feel victimized aligns with previous research indicating that those who endorse Right-wing authoritarianism attitudes tend to view the world as a dangerous place (Sibley, Wilson, \& Duckitt, 2007). Specifically, Sibley, Wilson, and Duckitt (2007) found that Right-wing authoritarianism had a reciprocal relationship with a dangerous worldview, such that individuals who viewed the world as a dangerous place at Time 1 were more likely to endorse Right-wing authoritarian attitudes at Time 2; conversely, those who endorsed Right-wing authoritarian attitudes at Time 1 were more likely to view the world as a dangerous place at Time 2. Thus, Right-wing authoritarianism is associated with an increased propensity to view the 
world as a threatening, dangerous place. Those high in Right-wing authoritarianism may feel that they are under attack, which logically may lead to an increased likelihood to feel victimized. This is consistent with the current findings, as teens who endorsed Right-wing authoritarian attitudes and rationalized harmful behavior through cognitive processes were more likely to selfreport feeling victimized, a potential result of this dangerous worldview.

Previous research has also found that individuals who are both victims and perpetrators of bullies tend to engage in a form of reactive, defensive aggression in response to perceived provocation (Card \& Little, 2006; Dodge, Lochman, Harnish, Bates, \& Pettit, 1997; Raine et al., 2006). Not surprisingly, individuals who feel victimized or targeted (whether or not they are truly being harassed) may lash out in defense, leading to an increase in bullying behavior - as may have been the case with these teens - or, as has been observed in current political and social events, verbal (and sometimes physical) harassment and abuse of others. More specifically, teens may use this sense of victimization to cognitively restructure or justify their subsequent aggression toward others, rationalizing their bullying behavior of others as an appropriate, moral response to being aggrieved. As Bandura (1999) noted, individuals utilize cognitive processes to rationalize their harmful behavior, allowing the individual to rid themselves of any feelings of wrongdoing. The teens in this sample who felt aggrieved may have used this sense of victimization to rationalize their subsequent aggression toward others.

Notably, the teens in this sample illustrated what is being seen on a global scale. These teens demonstrated that feeling victimized, targeted, and aggrieved paired with a greater propensity to aggress against those perceived as "other" (i.e., they have a greater sense of Rightwing authoritarianism) and an increased likelihood to rationalize this aggression (i.e., they have high levels of moral disengagement) can lead to the mistreatment of others. In other words, the 
current study demonstrated that the effect of teens' Right-wing authoritarian attitudes on bullying behavior is partially explained by their sense of being aggrieved. Further, this explanatory process of victimization was most pronounced for teens who engaged in the most cognitive restructuring. Teens who felt that they had been victimized and who were more likely to rationalize mistreatment of others (potentially due to their own perceived victimization) were ultimately more likely to aggress against others. Similarly, key political figures in the U.S. have painted a picture of victimhood for themselves and their followers as they claim that they are targets of repeated mistreatment (e.g., from the "fake media"). This feeling of aggrievement, as was observed in the current study, can lead to aggressive retaliation, and - through cognitive processes - rationalization of aggression toward others, particularly toward those who are perceived as "other." Thus, as claims of victimhood and blame of others becomes more rampant in the media, it regrettably does not come as a surprise that bullying and mistreatment of others has drastically increased (Anti-Defamation League, 2017; Southern Poverty Law Center, 2016).

Analyses also revealed that in addition to moderating the indirect relation between Rightwing authoritarianism and bullying behavior, moral disengagement also significantly moderated the direct relation between Right-wing authoritarianism and bullying behavior. In particular, Right-wing authoritarianism only directly impacted bullying behavior when levels of moral disengagement were high. In other words, teens' Right-wing authoritarian attitudes were associated with increased bullying of peers only when these teens also reported a greater propensity to rationalize or distance themselves from responsibility for their bullying behavior.

The integral role of moral disengagement in these indirect and direct relations is not surprising. Previous research has identified moral disengagement as a key correlate of bullying behavior (Bussey, Fitzpatrick, \& Raman, 2015; Perren \& Gutzwiller-Helfenfinger, 2012; Pornari 
\& Wood, 2010; Robson \& Witenberg, 2013; Runions \& Bak, 2015). For example, Bussey and colleagues (2015) found that higher levels of moral disengagement were associated with increased self-reported cyberbullying, while Perren and Gutzwiller-Helfenginer (2012) explained associations between moral disengagement and traditional bullying. Interestingly, Robson and Witenberg (2013) discovered that particular components of moral disengagement, such as moral justification and diffusion of responsibility, significantly predicted traditional bullying while attribution of blame and diffusion of responsibility predicted cyberbullying. Moral justification includes the cognitive restructuring of harmful behavior as righteous (Robson \& Witenberg, 2013). In terms of the current study, teens may have utilized moral justification to cognitively reframe their actions as justified. Further, attribution of blame is the process through which those who harm others blame someone else for their actions. Oftentimes, aggressors may victimblame, claiming that the victim of their mistreatment did something to deserve it. As Bandura (2002) eloquently put it, “[p]eople view themselves as faultless victims driven to injurious conduct for forcible provocation" (p. 110), emphasizing the cognitive reframing of harmful effects as justified, especially when one feels victimized. Importantly, in the current study, it was observed that teens who felt aggrieved were more likely to bully, especially when they tended to cognitively restructure their harmful behavior. This could indicate that teens feel justified in their aggressive responses to perceived victimization. It is conceptually consistent, then, that moral disengagement - when paired with a socio-cognitive attitude that increases the propensity for aggression toward others, such as Right-wing authoritarianism - contributes to increased harassment of others.

The current study has provided novel evidence indicating the existence of Right-wing authoritarianism - a socio-cognitive attitude that thus far has only been studied in adults - in an 
adolescent sample. In particular, it was found that adolescents who endorse Right-wing authoritarian attitudes and are high in moral disengagement display a greater propensity to feel victimized, resulting in increased bullying behavior. This suggests that adolescents are capable of believing in and acting upon such ideologies. Notably, the results of the current study are a consistent downward extension of the adult political science and social psychology literature. Adults who endorse Right-wing authoritarian attitudes view the world as a dangerous place (Sibley, Wilson, \& Duckitt, 2007); these teens may do so as well, as evidenced by their increased propensity to feel victimized when highly morally disengaged.

Further, as discussed previously, Right-wing authoritarianism has become associated with prejudice and discrimination among the adult literature, especially toward those not within one's “in-group" (Duckitt \& Sibley, 2007; Crawford, Brandt, Inbar, \& Mallinas, 2016; McCullough, Dispenza, Chang, \& Zeligman, 2019; Whitley, 1999). For example, a metaanalysis by Crawford and colleagues (2016) found an association between adults' endorsement of Right-wing authoritarianism and negative attitudes toward groups that are perceived to threaten traditional values, such as gay and lesbian individuals. Further, a meta-analysis by Jost et al. (2003) describes Right-wing authoritarianism's association with attitudes and behaviors such as racial prejudice, homophobia, political harassment, and such in adults. While Jost et al. (2003) slightly touch upon how Right-wing authoritarian values can influence parenting styles, research examining prejudice and discrimination rooted in Right-wing authoritarianism among children and adolescents is scarce.

Previous research has supported the existence of prejudiced dispositions rooted in Rightwing authoritarianism among adolescents (Duriez \& Soenens, 2009). In particular, Duriez and Soenens (2009) demonstrated that adolescent children of Right-wing authoritarian parents 
exhibited higher levels of racism explained by Right-wing authoritarianism. In other words, parents who endorsed Right-wing authoritarian attitudes also tended to score high on the racism scale, and children rated their own Right-wing authoritarian endorsement and subsequent racism similar to their parents (Duriez \& Soenens, 2009). The aforementioned study, then, clearly supports the existence of socio-cognitive attitudes such as Right-wing authoritarianism among teens. Congruently, the current study has demonstrated that Right-wing authoritarian attitudes are present among adolescents and likely contribute to their behavior.

\section{Limitations \& Future Research}

The current study had a few notable limitations. First, it was exclusively reliant upon selfreported data. Students may have attempted to answer in a socially desirable way despite the anonymous and confidential nature of the survey, and there is always the risk of memory bias. Further, the current study utilized a mono-informant/mono-method design. A monoinformant/mono-method design does not allow for the distinction between variance due to source and/or method effects and the effects of the target variables. In other words, while one can never entirely disentangle data from its source and the method with which it is collected, a monoinformant/mono-method design makes that disentanglement even harder. Utilizing different sources of data (such as teachers, caregivers, or peers) and various methods (such as interviews, ranking systems, etc.) would allow for more confident conclusions regarding the potential explanations of variance. Thus, while self-reports are useful in assessing socio-cognitive attitudes such as Right-wing authoritarianism and moral disengagement, future research might consider collecting data from multiple sources in regard to bullying behaviors. Peers, teachers, and caregivers might provide this additional information. Further, future research should utilize various methods for data collection. 
Second, there was a potential threat of selection bias and restricted range. While only four caregivers opted their child out of the study, a large number of students opted not to take the survey. Specifically, out of 497 freshmen students at the school, only 290 students began the survey, and multiple students' data were eliminated after their responses to the gender identity demographic question indicated that they may not have been responding seriously and honestly. For example, numerous students typed in the phrase "attack helicopter" after selecting the "Other" gender identity option. After a quick internet search, it was discovered that this phrase is a transphobic internet meme used to make fun of or criticize some gender identities. Right-wing authoritarianism has been associated with transphobia in previous research (McCullough, Dispenza, Chang, \& Zeligman, 2019; Nagoshi, Adams, Terrell, Hill, Brzuzy, \& Nagoshi, 2008), indicating that students responding with this phrase may be higher in Right-wing authoritarianism. However, their scales were removed from analysis, which could have potentially lessened the strength of the observed relationship between Right-wing authoritarianism and the other variables. Further, many students did not complete the survey, leading to incomplete data that ultimately were removed from analysis. The final sample size of 212 students consisted of a little less than $43 \%$ of the freshmen student population in this school. While attrition is not uncommon in school-based self-reports, one may wonder whether students with more extreme characteristics or attitudes were more or less likely to complete the survey. Self-selection in this way could lessen the variability of responses, leading to a restricted range that would attenuate associations among variables. At the school at which the surveys were administered, students were only scheduled to have one study hall period per week. Students may have opted to do school assignments instead of the survey during their one study hall period, thus limiting the data pool. Future research should attempt to assess a larger percentage 
of the student population and ensure that the final sample is representative of the student population at large.

\section{Conclusion}

The current study found novel evidence supporting the existence of Right-wing authoritarianism - a socio-cognitive attitude previously studied only in adults - among a sample of adolescents. Further, although moral disengagement has previously been studied within the bullying literature, less is known about moral disengagement's relationship with Right-wing authoritarianism and resulting behavior. Fascinatingly, Right-wing authoritarianism, when paired with high moral disengagement, led to an increased propensity to feel victimized. This perceived victimization, then, resulted in increased bullying behavior. hUnderstanding the relationship between certain socio-cognitive attitudes and bullying allows for schools to implement evidencebased curricular programming aimed at bullying prevention and reduction. Further, the current study demonstrates that adolescent attitudes may be negatively influenced by various media platforms, a potentially concerning prospect for educators and caregivers alike. Consumption of media such as the "attack helicopter" content described previously may lead to the adoption and endorsement of such prejudicial attitudes in adolescents. This study suggests that teens may not be immune to the harmful rhetoric broadcasted on various media platforms, and that the influence of media on teen attitudes should be taken into consideration during the creation and implementation of anti-bullying approaches.

Not only is a richer understanding of how these variables influence bullying behavior important for the implementation of bullying prevention and intervention techniques, it is also important for understanding the happenings of the world on a larger scale. Harassment is not exclusive to adolescents in a school setting. Current political discourse influences youth and 
adults alike and, more recently, has become increasing hostile and divisive. These hostile messages are not benign; rather, they may encourage and exacerbate existing attitudes and behaviors among certain groups, which can ultimately lead to an increase in harmful behavior toward others. Understanding how these socio-cognitive attitudes interact and influence behavior is imperative in addressing the rampant harassment and abuse seen on a global scale. 


\section{REFERENCES}

Almeida, A., Correia, I., \& Marinho, S. (2009). Moral disengagement, normative beliefs of peer group, and attitudes regarding roles in bullying. Journal of School Violence, 9, 23-36.

Altemeyer, B. (1981). Right-wing authoritarianism. Winnipeg, Ontario, Canada: University of Manitoba Press.

Anti-Defamation League. (2017). 2017 Audit of anti-Semitic incidents. Retrieved from https://www.adl.org/resources/reports/2017-audit-of-anti-semitic-incidents\#majorfindings.

Baldry, A. C., \& Farrington, D. P. (2000). Bullies and delinquents: Personal characteristics and parental styles. Journal of Community \& Applied Social Psychology, 10, 17-31. https://doi-org.libproxy.lib.ilstu.edu/10.1002/(SICI)1099-1298(200001/02)10:1<17::AIDCASP526>3.0.CO;2-M

Bandura, A. (1999). Moral disengagement in the perpetration of inhumanities. Personality and Social Psychology Review, 3, 193-209. doi:10.1207/s15327957pspr0303_3

Bandura, A., Barbaranelli, C., Caprara, G. V., \& Pastorelli, C. (1996). Mechanisms of moral disengagement in the exercise of moral agency. Journal of Personality and Social Psychology, 71, 364-374. doi:10.1037/0022-3514.71.2.364

Beck, C. L., \& Plant, E. A. (2018). The implications of right-wing authoritarianism for nonMuslims' aggression toward Muslims in the United States. Analyses of Social Issues and Public Policy (ASAP), 18, 353-377. https://doiorg.libproxy.lib.ilstu.edu/10.1111/asap.12163 
Bradshaw, C. P., Sawyer, A. L., \& O’Brennan, L. M. (2007). Bullying and peer victimization at school: Perceptual differences between students and school staff. School psychology review, 36, 361-382.

Bussey, K., Fitzpatrick, S., \& Raman, A. (2015). The role of moral disengagement and selfefficacy in cyberbullying. Journal of School Violence, 14, 30-46.

Card, N. A., \& Little, T. D. (2006). Proactive and reactive aggression in childhood and adolescence: A meta-analysis of differential relations with psychosocial adjustment. International Journal of Behavioral Development, 30, 466-480. https://doi.org/10.1177/0165025406071904

Chaux, E., Molano, A., \& Podlesky, P. (2009). Socio-economic, socio-political and socioemotional variables explaining school bullying: A country-wide multilevel analysis. Aggressive Behavior: Official Journal of the International Society for Research on Aggression, 35, 520-529.

Craig, M. A., \& Richeson, J. A. (2014). Not in my backyard! Authoritarianism, social dominance orientation, and support for strict immigration policies at home and abroad. Political Psychology, 35, 417-429.

Crawford, J. T., Brandt, M. J., Inbar, Y., \& Mallinas, S. R. (2016). Right-wing authoritarianism predicts prejudice equally toward "gay men and lesbians" and "homosexuals." Journal of Personality and Social Psychology, 111, e31-e45. https://doiorg.libproxy.lib.ilstu.edu/10.1037/pspp0000070.supp (Supplemental)

Crick, N. R., \& Dodge, K. A. (1999). "Superiority" is in the eye of the beholder: A comment of Sutton, Smith and Swettenham. Social Development, 8, 128-131. https://doiorg.libproxy.lib.ilstu.edu/10.1111/1467-9507.00084 
Crick, N. R., \& Dodge, K. A. (1994). A review and reformulation of social informationprocessing mechanisms in children's social adjustment. Psychological bulletin, 115, 74.

Crick, N. R., \& Grotpeter, J. K. (1996). Children's treatment by peers: Victims of relational and overt aggression. Development and Psychopathology, 8, 367-380.

Crick, N. R., \& Grotpeter, J. (1995). Relational aggression, gender, and social-psychological adjustment. Child Development, 66, 710-722.

Dodge, K. A. (1980). Social cognition and children's aggressive behavior. Child Development, $51,162-170$.

Dodge, K. A., Lochman, J. E., Harnish, J. D., Bates, J. E., \& Pettit, G. S. (1997). Reactive and proactive aggression in school children and psychiatrically impaired chronically assaultive youth. Journal of Abnormal Psychology, 106, 37.

Duckitt, J., \& Sibley, C. G. (2007). Right wing authoritarianism, social dominance orientation and the dimensions of generalized prejudice. European Journal of Personality, 21, 113130. https://doi-org.libproxy.lib.ilstu.edu/10.1002/per.614

Duriez, B. \& Soenens, B. (2009). The intergenerational transmission of racism: The role of rightwing authoritarianism and social dominance orientation. Journal of Research in Personality, 43, 906-909.

Evans, S. C., Frazer, A. L., Blossom, J. B., \& Fite, P. J. (2019). Forms and functions of aggression in early childhood. Journal of Clinical Child and Adolescent Psychology, 48, 790-798. https://doi-org.libproxy.lib.ilstu.edu/10.1080/15374416.2018.1485104

Hayes, A. F. (2017). Introduction to mediation, moderation, and conditional process analysis: A regression-based approach. Guilford publications. 
Haynie, D. L., Nansel, T., Eitel, P., Crump, A. D., Saylor, K., Yu, K., \& Simons-Morton, B. (2001). Bullies, victims, and bully/victims: Distinct groups of at-risk youth. The Journal of Early Adolescence, 21, 29-49.

Holt, M. K., \& Espelage, D. L. (2007). Perceived social support among bullies, victims, and bully-victims. Journal of Youth and Adolescence, 36, 984-994.

Hymel, S., Rocke-Henderson, N., \& Bonanno, R. A. (2005). Moral disengagement: A framework for understanding bullying among adolescents. Journal of Social Sciences, 8, 1-11.

Illinois State Board of Education. (2019). Illinois Report Card. Retrieved from https://www.illinoisreportcard.com/

Johnson, D. D., McDermott, R., Cowden, J., \& Tingley, D. (2012). Dead certain. Human Nature, 23, 98-126.

Jost, J. T., Federico, C. M., \& Napier, J. L. (2009). Political ideology: Its structure, functions, and elective affinities. Annual Review of Psychology, 60, 307-337.

Knafo, A. (2003). Authoritarians, the next generation: Values and bullying among adolescent children of authoritarian fathers. Analyses of Social Issues and Public Policy, 3, 199-204.

Kvarme, L.G., Helseth, S., Sæteren, B., \& Natvig, G.K. (2010). School children's experience of being bullied and how they envisage their dream day. Scandinavian Journal of Caring Sciences, 24, 791-798.

McCullough, R., Dispenza, F., Chang, C. Y., \& Zeligman, M. R. (2019). Correlates and predictors of anti-transgender prejudice. Psychology of Sexual Orientation and Gender Diversity, 6, 359-368. https://doi-org.libproxy.lib.ilstu.edu/10.1037/sgd0000334

Nagoshi, J. L., Adams, K. A., Terrell, H. K., Hill, E. D., Brzuzy, S., \& Nagoshi, C. T. (2008). Gender differences in correlates of homophobia and transphobia. Sex roles, 59, 521-531. 
Nansel, T. R., Overpeck, M., Pilla, R. S., Ruan, W. J., Simons-Morton, B., \& Scheidt, P. (2001). Bullying behaviors among US youth: Prevalence and association with psychosocial adjustment. Journal of the American Medical Association, 285, 2094-2100.

National Center for Education Statistics (2019, April). Indicators of school crime and safety. Retrieved November 3, 2019, from https://nces.ed.gov/programs/crimeindicators/ind_10.asp.

Obermann, M. L. (2011). Moral disengagement among bystanders to school bullying. Journal of School Violence, 10, 239-257.

Perren, S., \& Gutzwiller-Helfenfinger, E. (2012). Cyberbullying and traditional bullying in adolescence: Differential roles of moral disengagement, moral emotions, and moral values. European Journal of Developmental Psychology, 9, 195-209.

Pornari, C. D., \& Wood, J. (2010). Peer and cyber aggression in secondary school students: The role of moral disengagement, hostile attribution bias, and outcome expectancies. Aggressive Behavior: Official Journal of the International Society for Research on Aggression, 36, 81-94.

Pratto, F., Sidanius, J., Stallworth, L. M., \& Malle, B. F. (1994). Social dominance orientation: A personality variable predicting social and political attitudes. Journal of Personality and Social Psychology, 67, 741-763. doi:10.1037//0022-3514.67.4.741

Raine, A., Dodge, K., Loeber, R., Gatzke-Kopp, L., Lynam, D., Reynolds, C., ... \& Liu, J. (2006). The reactive-proactive aggression questionnaire: Differential correlates of reactive and proactive aggression in adolescent boys. Aggressive Behavior: Official Journal of the International Society for Research on Aggression, 32, 159-171. 
Reijntjes, A., Vermande, M., Olthof, T., Goossens, F. A., Van De Schoot, R., Aleva, L., \& Van Der Meulen, M. (2013). Costs and benefits of bullying in the context of the peer group: A three wave longitudinal analysis. Journal of Abnormal Child Psychology, 41, 1217-1229.

Robson, C., \& Witenberg, R. T. (2013). The influence of moral disengagement, morally based self-esteem, age, and gender on traditional bullying and cyberbullying. Journal of School Violence, 12, 211-231.

Runions, K. C., \& Bak, M. (2015). Online moral disengagement, cyberbullying, and cyberaggression. Cyberpsychology, Behavior, and Social Networking, 18, 400-405.

Runions, K. C., Shaw, T., Bussey, K., Thornberg, R., Salmivalli, C., \& Cross, D. S. (2019). Moral disengagement of pure bullies and bully/victims: Shared and distinct mechanisms. Journal of Youth and Adolescence, 48, 1835-1848. https://doiorg.libproxy.lib.ilstu.edu/10.1007/s10964-019-01067-2

Salmivalli, C., Lagerspetz, K., Björkqvist, K., Österman, K., \& Kaukiainen, A. (1996). Bullying as a group process: Participant roles and their relations to social status within the group. Aggressive Behavior, 22, 1-15. https://doiorg.libproxy.lib.ilstu.edu/10.1002/(SICI)1098-2337(1996)22:1<1::AID-AB1>3.0.CO;2-T

Salmivalli, C., Sainio, M., \& Hodges, E. V. (2013). Electronic victimization: Correlates, antecedents, and consequences among elementary and middle school students. Journal of Clinical Child \& Adolescent Psychology, 42, 442-453.

Salmivalli, C., Voeten, M., \& Poskiparta, E. (2011). Bystanders matter: Associations between reinforcing, defending, and the frequency of bullying behavior in classrooms. Journal of Clinical Child \& Adolescent Psychology, 40, 668-676. 
Scholte, R. H., Engels, R. C., Overbeek, G., De Kemp, R. A., \& Haselager, G. J. (2007). Stability in bullying and victimization and its association with social adjustment in childhood and adolescence. Journal of Abnormal Child Psychology, 35, 217-228.

Sibley, C. G., Wilson, M. S., \& Duckitt, J. (2007). Effects of dangerous and competitive worldviews on right-wing authoritarianism and social dominance orientation over a fivemonth period. Political Psychology, 28, 357-371.

Solomontos-Kountouri, O., Tsagkaridis, K., Gradinger, P., \& Strohmeier, D. (2017). Academic, socio-emotional and demographic characteristics of adolescents involved in traditional bullying, cyberbullying, or both: Looking at variables and persons. International Journal of Developmental Science, 11, 19-30. https://doi-org.libproxy.lib.ilstu.edu/10.3233/DEV17219

Southern Poverty Law Center (2016). The Trump Effect: The impact of the 2016 presidential election on our nation's schools. Retrieved from https://www.splcenter.org/20161128/trump-effect-impact-2016-presidential-election-our$\underline{\text { nations-schools }}$

Stefanek, E., Strohmeier, D., \& Yanagida, T. (2017). Depression in groups of bullies and victims: Evidence for the differential importance of peer status, reciprocal friends, school liking, academic self-efficacy, school motivation and academic achievement. International Journal of Developmental Science, 11, 31-43. https://doiorg.libproxy.lib.ilstu.edu/10.3233/DEV-160214

Sutton, J., Smith, P. K., \& Swettenham, J. (1999). Social cognition and bullying: Social inadequacy or skilled manipulation?. British Journal of Developmental Psychology, 17, 435-450. 
Thomas, H. J., Scott, J. G., Coates, J. M., \& Connor, J. P. (2019). Development and validation of the Bullying and Cyberbullying Scale for Adolescents: A multi-dimensional measurement model. British Journal of Educational Psychology, 89, 75-94.

U.S. Department of Health and Human Services. (2019). What is bullying. Retrieved from https://www.stopbullying.gov/what-is-bullying/index.html.

Veenstra, R., Lindenberg, S., Oldehinkel, A. J., Winter, A. F. D., Verhulst, F. C., \& Ormel, J. (2005). Bullying and victimization in elementary schools: A comparison of bullies, victims, bully/victims, and uninvolved preadolescents. Developmental Psychology, 41, 672-682. doi: 10.1037/0012-1649.41.4.672

Warden, D., \& Mackinnon, S. (2003). Prosocial children, bullies and victims: An investigation of their sociometric status, empathy and social problem-solving strategies. British Journal of Developmental Psychology, 21, 367-385. https://doiorg.libproxy.lib.ilstu.edu/10.1348/026151003322277757

Whitley Jr, B. E. (1999). Right-wing authoritarianism, social dominance orientation, and prejudice. Journal of Personality and Social Psychology, 77, 126.

Williams, K. R., \& Guerra, N. G. (2007). Prevalence and predictors of internet bullying. Journal of Adolescent Health, 41, S14-S21. doi: 10.1016/j.jadohealth.2007.08.018

Wilson, M. S., \& Sibley, C. G. (2013). Social dominance orientation and right-wing authoritarianism: Additive and interactive effects on political conservatism. Political Psychology, 34, 277-284.

Wolke, D., Copeland, W. E., Angold, A., \& Costello, E. J. (2013). Impact of bullying in childhood on adult health, wealth, crime, and social outcomes. Psychological Science, 24, 1958-1970. doi:10.1177/0956797613481608 
Wolke, D., \& Lereya, S. T. (2015). Long-term effects of bullying. Archives of Disease in Childhood, 100, 879-885. doi:10.1136/archdischild-2014-306667

Ziv, Y., Leibovich, I., \& Shechtman, Z. (2013). Bullying and victimization in early adolescence: Relations to social information processing patterns. Aggressive Behavior, 39, 482-492. 


\section{APPENDIX A: ALTERED BULLYING AND CYBERBULLYING SCALE FOR}

ADOLESCENTS (BCS-A; THOMAS, SCOTT, COATES, \& CONNOR, 2019)

How many times in the past month (30 days) has this been DONE TO YOU by another person

\section{“OFFLINE" / FACE-TO-FACE?}

1. Punched, hit, kicked, pushed or shoved me, on purpose.

2. Forced me to do something I did not want to do.

3. Told me others would not like me if I did not do what they said.

4. Damaged, hid, or stole my belongings, on purpose.

5. Called me mean or hurtful names.

6. Said mean or hurtful things to me.

7. Left me out of a group or an activity, or did not allow me to join in, on purpose.

8. Spread lies or rumors about me to hurt me or make others not like me.

How many times in the past month (30 days) has this been DONE TO YOU by another person "ONLINE" / ON THE INTERNET / THROUGH SOCIAL MEDIA?

1. Call me mean or hurtful names.

2. Sent or posted mean or hurtful pictures/videos about me.

3. Told me others would not like me if I did not do what they said.

4. Left me out of a group or an activity, or did not allow me to join in, on purpose.

5. Spread lies or rumors about me to hurt me or make others not like me.

6. Sent me a hateful or mean direct message (DM). 
How many times in the past month (30 days) have YOU DONE the following to another person "OFFLINE" / FACE-TO-FACE - on your own or as part of a group?

1. Punched, hit, kicked, pushed or shoved someone, on purpose.

2. Forced someone to do something they did not want to do.

3. Told someone that others would not like them if they did not do what I/we said.

4. Damaged, hid, or stole someone's belongings, on purpose.

5. Called someone mean or hurtful names.

6. Said mean or hurtful things to someone.

7. Left someone out of a group or an activity, or did not allow them to join in, on purpose.

8. Spread false rumors about a person to hurt them or make others not like them.

How many times in the past month (30 days) have YOU DONE the following to another person "ONLINE" / ON THE INTERNET / THROUGH SOCIAL MEDIA - on your own or as part of a group?

1. Called someone mean or hurtful names.

2. Sent or posted mean or hurtful pictures/videos about someone.

3. Told someone that others would not like them if they did not do what I/we said.

4. Left someone out of a group or an activity, or did not allow them to join in, on purpose.

5. Spread lies or rumors about someone to hurt them or make others not like them.

6. Sent another student a hateful or mean direct message ("DM").

(Response options: never, once or twice, several times, a lot of times) 


\section{APPENDIX B: ADAPTED RWA SCALE (ALTEMEYER, 1981)}

Please indicate your level of agreement or disagreement with each of the following statements.

1. The government is always right and people who protest are showing their ignorance.

2. Women should always obey their husbands once they are married.

3. Members of the LGBTQ community are just as healthy and moral as everybody else.

4. We must trust leaders in government and religion and not be influenced by people who complain about our leaders.

5. Those who are not involved with an established religion are as good as those who attend church regularly.

6. Our country has too many trouble-makers and we need a strong leader with traditional values.

7. Our country needs free thinkers who have the courage to speak up against traditional values, even if this upsets other people.

8. Our country will be destroyed one day if we do not have strong leaders with traditional values.

9. Everyone should have their own lifestyle, religious beliefs, and sexual preferences, even if it makes them different from everyone else.

10. The "old-fashioned ways" and the "old-fashioned values" still show the best way to live.

11. You have to admire those who speak out in support of women's rights and animal rights.

12. What our country needs is a strong, determined leader who will take us back to a better time.

13. Some of the best people in our country are those who challenge the wisdom of authority figures. 
14. The days a woman should be submissive belong strictly in the past.

15. Our country will be great if we do what the authorities tell us to do and we ignore those who disagree with authority.

16. There is no "one right way" to live life; everybody has to create their own way.

17. Members of the LGBTQ community and feminists should be praised for being brave enough to defy "traditional family values."

18. This country would work a lot better if certain groups would just shut up and accept things as they are.

(Response options: strongly disagree, disagree, agree, strongly agree) 


\section{APPENDIX C: ABBREVIATED MORAL DISENGAGEMENT SCALE (MDS; BANDURA}

$$
\text { ET AL., 1996) }
$$

Please indicate the extent to which you agree or disagree with each of the following statements.

1. Some groups of people are simply not as good as other groups.

2. In getting what you want, it is sometimes necessary to take advantage of other groups of people.

3. It's OK if some groups of people have a greater chance in life than other groups of people.

4. If certain groups of people accepted things as they are, we would have fewer problems.

5. It's probably a good thing that certain groups of people are at the top and other groups are at the bottom.

6. Sometimes people in other groups must be reminded to stay in their place.

7. It would be good if all groups of people could be considered equal.

8. Our country must strive for group equality.

9. All groups should be given an equal chance in life.

10. We should do what we can to give the same opportunities to all groups of people.

11. We would have fewer problems if we treated all people the same.

12. No one group should dominate in our society.

(Response options: strongly disagree, disagree, agree, strongly agree) 